\section{Results}

All the patients achieved a lasting erection with the device, and none experienced any unpleasant side effects. Some noticed minor discomfort during the first week of use but none thereafter. Most patients commented that adequate lubrication was essential for effective use. Only one couple was not using the device regularly because of marital disharmony.

The table shows the patients' and partners' assessments. Three partners were not willing to complete the questionnaire and were still finding it difficult to come to terms with using the device. Overall reaction varied from the superlative to the satisfied, and in only one case was the relationship not improved. Four of the patients had begun to achieve, but not maintain, erection without the device, and couples were having intercourse an average of six (0-18) times a month.

\section{Discussion}

This device provides a practical alternative for the management of erectile impotence in diabetic men. ErecAid is safe, non-invasive, and readily reversible, perhaps making extensive investigation to establish the relative importance of the potential aetiological factors less essential to the management. Psychosexual counselling may still be necessary, as for one of the couples described here, but in general removal of the threat of failure is itself of great therapeutic value.

When explaining the use of the device, I have found it preferable to talk to the couple together, and the system has been most effective when used by those couples prepared to discuss it openly and when the partner has been happy for the device to be incorporated into lovemaking. When inhibitions remained, the system was less successful.

ErecAid may not be used to treat all cases of erectile impotence, but for most couples it is a safe, fairly inexpensive, and simple means of managing impotence, particularly among patients with
Assessment of ErecAid by patients and partners after three month' use. Scores were given on visual analogue scales and are expressed as means (SEM)

\begin{tabular}{lcc}
\hline & Patients (n=10) & Partners (n=7) \\
\hline Scale 0 to 10: & $7 \cdot 8(0 \cdot 6)$ & $7 \cdot 8(1 \cdot 2)$ \\
$\quad$ Ease of using device & $8 \cdot 5(0 \cdot 5)$ & $7 \cdot 6(0 \cdot 6)$ \\
Effectiveness of device & $7 \cdot 5(0 \cdot 6)$ & $7 \cdot 2(0 \cdot 8)$ \\
Satisfaction with erection & $6 \cdot 2(1 \cdot 0)$ & $6 \cdot 9(1 \cdot 3)$ \\
Partner's satisfaction & $2 \cdot 6(0 \cdot 8)$ & $3 \cdot 0(0 \cdot 9)$ \\
Scale -5 to +5: & $2 \cdot 1(0 \cdot 8)$ & $1 \cdot 7(0 \cdot 8)$ \\
Change in overall relationship with partner & & \\
Change in self esteem & & \\
\hline
\end{tabular}

diabetes or other organic causes. It may also be a useful adjunct to psychosexual counselling in patients with psychogenic impotence.

I thank Dr J K Wales for allowing me to study his patients and Mrs Kim Ely for typing the manuscript.

\section{References}

1 McCullock DK, Campbell IW, Wu FC, Prescott RJ, Clarke BF. The prevalence of diabetic impotence. Diabetologia 1980;18:279-83.

2 Martin LM. Impotence in diabetes: an overview. Psychosomatics 1981;22:318-29.

3 McCullock DK, Hosking DJ, Tobert A. A pragmatic approach to sexual dysfunction in diabetic men: psychosexual counselling. Diabetic Medicine 1986;3:485-9.

4 Beaser AS, Van der Hock C, Jacobsen AM, Flood TM, Desautels RE. Experience with penile prostheses in the treatment of impotence in diabetic men. JAMA 1982;248:943-8.

5 Sidi AA, Cameron JS, Duffy LM, Lange PH. Intracavernous drug induced erections in the management of male erectile disfunction: experience with 100 patients. $\mathcal{F}$ Urol 1986;135:704-6. 6 Nadig PW, Ware JC, Blumoff R. Non-invasive device to produce and maintain an erection-like state. Urology 1986;27:126-31.

(Accepted 8 October 1987)

\title{
Medical cost of curing childhood acute lymphoblastic leukaemia
}

\author{
KATE WHEELER，ALISON D LEIPER， LEILA JANNOUN，JUDITH M CHESSELLS
}

\begin{abstract}
Between 1970 and 1979 acute lymphoblastic leukaemia was diagnosed in 378 children at this hospital. The outcome for the 181 survivors was examined six or more years after diagnosis to assess morbidity in an unselected group of long term survivors. One hundred and thirty seven of the survivors were in first remission and probably cured (group I). Forty four (group II) had had one or more relapses, some of whom, who had isolated extramedullary relapses, also have a good chance of cure.

In group I 136 patients had prophylactic cranial or craniospinal irradiation, while patients in group II, in addition to having that treatment, received local testicular (17) or craniospinal radiation (seven) for testicular or central nervous system relapse. Eight had additional prophylactic cranial radiotherapy after bone marrow relapse, and six had total body irradiation before bone
\end{abstract}

Department of Haematology/Oncology, Hospital for Sick Children, London WC1N 3JH

KATE WHEELER, MB, MRCP, leukaemia research fellow

ALISON D LEIPER, MB, MRCP, associate specialist

LEILA JANNOUN, PHD, clinical psychologist

JUDITH M CHESSELLS, MD, FRCP, consultant haematologist

Correspondence to: Dr Wheeler. marrow transplantation. The incidence of clinically important growth and endocrine morbidity was $20 \%$ in group $I$ and $68 \%$ in group II. The morbidity in patients in group I was mainly attributable to early pubertal maturation. In group II 30 patients had growth failure, of whom 19 had gonadal failure from testicular or total body irradiation, 14 had growth hormone deficiency after doses of cranial irradiation of over $2400 \mathrm{cGy}$, and 10 had spinal growth impairment after craniospinal irradiation. Two also had early pubertal maturation. Five out of six patients who received total body irradiation had multiple endocrine deficiency. Neuropsychological sequelae of treatment were seen in $40(42 \%)$ of 96 schoolchildren in group $I$ and in $12(38 \%)$ of 32 schoolchildren in group II. Postinfective sequelae of treatment were found in patients in both groups.

These results show that the survivors who were in their first remission had a $42 \%$ residual morbidity related to treatment compared with an $82 \%$ morbidity in the survivors of one or more relapses who had multiple treatments.

\section{Introduction}

The number of long term survivors of childhood acute lymphoblastic leukaemia has steadily increased over the past decade. Many of these patients, who are probably "cured," are approaching 
adolescence and adulthood, and it is important to assess their quality of life and identify the long term sequelae of treatment. We analysed the outcome of a cohort of patients who were referred to this hospital after multiagent chemotherapy regimens and central nervous system prophylaxis were introduced, and who were followed up for a minimum of six years. We examined two groups of survivors. Group I consists of all disease free survivors in first remission six years or more after diagnosis who received only one course of treatment, and most can be considered "cured." Group II consists of patients who were alive at least six years after diagnosis who had one or more relapses and received a minimum of two courses of treatment, which often included further radiation treatment. We compared some aspects of the morbidity in the two groups of patients.

Central nervous system prophylaxis using cranial irradiation and intrathecal methotrexate was introduced in 1972 to prevent overt leukaemic infiltration of the meninges. The effect of this was a profound reduction in the central nervous system relapse rate but at the expense of impaired intellectual ability ${ }^{1-4}$ and pituitary function. ${ }^{5}$ In the late 1970 s it was reported that growth hormone deficiency after cranial irradiation of over 2400 cGy occurred. ${ }^{5}$ Over the past year, however, partial or complete growth hormone deficiency has been increasingly recognised in patients who have received $2400 \mathrm{cGy}$ or less of prophylactic cranial irradiation, ${ }^{67}$ and some growth impairment in patients with acute lymphoblastic leukaemia is now considered to be common. ${ }^{8}$ In many patients, however, this is not clinically important. ${ }^{8}$ Our routine growth assessment has not included bone age estimations until recently, and it has not been possible therefore to draw conclusions about minor growth impairment from our current data. Clinically important problems of growth have, however, been analysed and are reported in this study in addition to other aspects of morbidity.

\section{Patients and methods}

The patients came from an unselected group of 378 children, all of whom had been referred to the hospital in the 10 years from 1970 to 1979 for treatment of acute lymphoblastic leukaemia. They were treated with protocols devised by or being piloted for the Medical Research Council Working Party on Leukaemia in Childhood. ${ }^{9}$ All received induction therapy with vincristine, prednisolone, and at least one other drug, and all received 2400 cGy cranial irradiation and intrathecal methotrexate, except those in UKALL I who received delayed central nervous system prophylaxis and in one case none. Eighteen patients in UKALL II received both $2400 \mathrm{cGy}$ cranial and $1000 \mathrm{cGy}$ spinal irradiation. All had continuing maintenance therapy for two or three years. One patient in UKALL VI received prophylactic testicular irradiation (1500 cGy).

Patients who had a bone marrow relapse were treated in a variety of ways and also in later years by bone marrow transplantation after high dose cyclophosphamide and total body irradiation: four patients (three boys and one girl) were prepubertal at the time of bone marrow transplantation and two (one boy and one girl) pubertal. Isolated extramedullary relapse in the central nervous system or testis was treated with reinduction, often intensification of systemic treatment, and fractionated local irradiation consisting of craniospinal radiotherapy (cranial $2400 \mathrm{cGy}$ and spinal $1000 \mathrm{cGy}$ ) in the case of central nervous system relapse, and testicular radiotherapy ( $2400 \mathrm{cGy}$ ) for testicular relapse, followed by continuing chemotherapy for a further two to three years.

The current state of the children was assessed at six years or more after treatment. Since there was no control group the morbidity found in this group of patients includes the natural morbidity found in any group of children.

Routine clinical assessment included growth and social assessment and psychological testing. Psychological testing was undertaken in almost all patients in group I. Standing height was measured using a Stadiometer at three monthly intervals and compared with the standards for British children. ${ }^{10}$ Growth failure in prepubertal children was defined as a consistently low growth velocity measured over a one year period. During puberty growth failure was considered to have occurred when there was an absence of the normal harmony between the stage of sexual maturation and the onset of growth acceleration ${ }^{11}$ as well as the magnitude of the peak height velocity achieved during growth acceleration. When growth failure occurred serial measurements were taken by standard anthropometric techniques, including standing and sitting height and serial bone age assessments by the method of Tanner et al. ${ }^{12}$ Where indicated hypothalamopituitary function was assessed in a combined test of intravenous insulin induced hypoglycaemia $(0.1 \mathrm{unit} / \mathrm{kg})$, intravenous luteinising hormone releasing hormone $(100 \mu \mathrm{g})$, and intravenous thyrotrophin releasing hormone $(200 \mu \mathrm{g})$ by standard techniques. ${ }^{13}$ Prepubertal patients who had a bone age of 9 years or more were "primed" using testosterone esters (Sustanon $100 \mathrm{mg}$ intramuscularly) seven days before the test for boys and ethinyloestradiol ( $50 \mu \mathrm{g}$ daily) for three days before the test for girls. ${ }^{1}$ The patients who had bone marrow transplantation were routinely investigated in this way a minimum of 18 months after transplantation, as endocrine deficiency is usually delayed.

Gonadal function was investigated in those who had received either local testicular radiotherapy or total body irradiation, using basal plasma testosterone and oestradiol concentrations and basal serum luteinising hormone and follicle stimulating hormone concentrations and in some patients by the gonadotrophin response to intravenous luteinising hormone releasing hormone. All survivors in first remission were assessed using a standardised intelligence test, usually at least two years after treatment was stopped. The British ability scales, which provide measures of intellectual ability based on British norms, ${ }^{14}$ were used on patients under 6 years of age and the Wechsler intelligence scale for children ${ }^{15}$ was used on older children. The similarities, arithmetic vocabulary, and digit span scaled scores were prorated to provide an estimate of verbal IQ, and block design object assembly and codings were prorated to measure performance IQ. Information on school performance was obtained from the school and parents. In the school leavers information on job status was sought.

The IQ results were analysed using a Student's $t$ test.

\section{Results}

Six years after diagnosis 202 patients (53\%) were alive: 140 in first remission and 62 after one or more relapses. Three of the 140 patients in first remission subsequently relapsed, thus leaving 137 in group $I$. The outcome of the 62 relapsed patients has been reviewed elsewhere. ${ }^{16}$ Group II comprises 44 patients - the 42 survivors of the 62 relapsed patients and the two surviving patients with late bone marrow relapses from group I. Tables I and II give details of these patients and their treatment.

TABLE I-Details of patients in groups I and II. (Median in parentheses)

\begin{tabular}{lcc}
\hline & Group I & Group II \\
\hline No & 137 & 44 \\
Disease states: & 137 & \\
1st remission & & 31 \\
2nd remission & & 11 \\
3rd remission & 2 \\
4th remission & $0 \cdot 5-14(4)$ & $1-13 \cdot 5(4)$ \\
Age at diagnosis (years) & $67: 70$ & $31: 13(12$ with testicular relapse) \\
M:F & $6-16(10)$ & $6-16(10)$ \\
Time for diagnosis (years) & $8-25(15)$ & $9 \cdot 5-24(16)$ \\
Age at assessment (years) & & \\
\hline
\end{tabular}

TABLE II-Details of treatment of patients in groups I and II

\begin{tabular}{|c|c|c|}
\hline & Group I & Group II \\
\hline Alive: no relapse & 137 & \\
\hline Alive: more than one relapse: & & 44 \\
\hline Bone marrow once & & 19 \\
\hline Testicular once & & 12 \\
\hline Central nervous system + bone marrow once & & 8 \\
\hline Multiple & & 5 \\
\hline \multicolumn{3}{|l|}{ Courses of chemotherapy ${ }^{\star}$ : } \\
\hline 1 & 137 & \\
\hline 2 & & 31 \\
\hline 3 & & 7 \\
\hline Receiving treatment & & 6 \\
\hline \multicolumn{3}{|l|}{ Radiotherapy: } \\
\hline Cranial once ( $2400 \mathrm{cGy})$ & 119 & 17 \\
\hline Craniospinal once (cranial 2400 cGy, spinal 1000 cGy) & 17 & 6 \\
\hline Testicular once ( $2400 \mathrm{cGy})$ & 1 & $17 \dagger$ \\
\hline Cranial twice & & 8 \\
\hline Cranial+craniospinal & & 7 \\
\hline $\begin{array}{l}\text { Total body irradiation }(1000 \mathrm{cGy} \text {, single fraction) (with bone } \\
\text { marrow transplantation) + cranial once }\end{array}$ & & 6 \\
\hline None & 1 & \\
\hline
\end{tabular}

$\star$ Duration $=$ two to three years.

†Additional radiotherapy in these patients: 12 cranial once; three cranial+craniospinal; two total body irradiation. 
Three patients in the original cohort of 378 developed second tumours within six years of diagnosis: acute myeloid leukaemia, cervical cystic astrocytoma, and Hodgkin's disease, but none survived. Table III summarises the long term sequelae of treatment in both groups of patients.

TABLE III-Comparison of morbidity in groups I and II (percentages in parentheses)

\begin{tabular}{lcc}
\hline \multicolumn{1}{c}{ Morbidity } & $\begin{array}{c}\text { Group I } \\
(\mathrm{n}=137)\end{array}$ & $\begin{array}{c}\text { Group II } \\
(\mathrm{n}=44)\end{array}$ \\
\hline Growth and endocrine & $28(20)$ & $30(68)$ \\
Neuropsychological & $40(29)$ & $14(32)$ \\
Postinfective & $8(6)$ & $3(7)$ \\
Other & $1(0 \cdot 7)$ & $8(18)$ \\
No of "problem free" patients & $80(58)$ & $8(18)$ (four are prepubertal) \\
\hline
\end{tabular}

Note: Fifteen patients in group I and 14 patients in group II have multisystem morbidity.

TABLE IV-Growth and endocrine data on patients in group II

\begin{tabular}{|c|c|c|c|c|c|}
\hline Radiotherapy treatment & No & $\begin{array}{l}\text { Reduced } \\
\text { sitting } \\
\text { height }\end{array}$ & $\begin{array}{l}\text { Growth } \\
\text { hormone } \\
\text { deficiency }\end{array}$ & $\begin{array}{l}\text { Gonadal } \\
\text { failure }\end{array}$ & $\begin{array}{l}\text { Early } \\
\text { puberty }\end{array}$ \\
\hline $\begin{array}{l}\text { Cranial once ( } 2400 \mathrm{cGy}) \\
\text { Craniospinal once (cranial }\end{array}$ & 5 & & & & \\
\hline $\begin{array}{l}\text { Craniospinal once (cranial } \\
2400 \mathrm{cGy} \text {, spinal } 1000 \mathrm{cGy} \text { ) }\end{array}$ & 6 & 4 & - & & 1 \\
\hline $\begin{array}{l}\text { Cranial once }(2400 \mathrm{cGy})+ \\
\text { craniospinal once }(2400 \mathrm{cGy}, \\
\text { spinal } 1000 \mathrm{cGy})\end{array}$ & 7 & 6 & 5 & & \\
\hline Cranial twice ( $4800 \mathrm{cGy})$ & 8 & & 4 & & 1 \\
\hline Testicular $(2400 \mathrm{cGy})^{\star}$ & 17 & & & 15 & \\
\hline $\begin{array}{l}\text { Total body irradiation (900 cGy, } \\
\text { single fraction) }\end{array}$ & 6 & 5 & 5 & 4 & \\
\hline
\end{tabular}

^Five testicular radiotherapy patients presented in table twice as additional radiotherapy: three cranial +craniospinal; two total body irradiation.
The remaining 109 children have grown or appear to be growing at a satisfactory velocity, although we do not have sufficient growth data to comment on minor impairment. The incidence of clinically importan endocrine morbidity is $20 \%$, however.

\section{Group II}

Table IV summarises the results from group II. Growth failure is common. Fourteen patients have growth hormone deficiency due to crania or craniospinal irradiation of more than $2400 \mathrm{cGy}$ or to total body irradiation. This was proved biochemically in nine (peak growth hormone in response to insulin induced hypoglycaemia $<20 \mathrm{mU} / \mathrm{l}$ ) who require growth hormone supplementation. The other five patients have not been investigated, as epiphysial fusion and final height attainment has already occurred, but they have anthropometric evidence of growth hormone deficiency. Of the 13 patients who had craniospinal irradiation, 10 have appreciably reduced sitting height measurements and five also have growth hormone deficiency (peak growth hormone $<20 \mathrm{mU} / \mathrm{l}$ ). Only three of these patients exhibit normal growth velocities, and none has anthropometric evidence of growth hormone deficiency.

Nineteen patients (17 male and two female) have gonadal failure after testicular irradiation or total body irradiation, which is compensated in five but requires sex hormone supplementation in 14 . Two girls have evidence of early puberty (stage II breast development $9 \cdot 0$ and $\mathbf{9 \cdot 4}$ years: age at menarche 10.0 and 10.5 years). One had an early growth spurt with probable reduction in final height (25th centile at 9 years; final heigh less than the third centile), while the other also has growth hormone deficiency and did not show a growth spurt until growth hormone treatment was started.

Only 14 patients currently have normal growth velocities. These include the seven patients who received one course only of cranial or craniospinal irradiation ( $2400 \mathrm{cGy}$ ), five patients (two of whom are still prepubertal) who received two courses of cranial or craniospinal irradiation (4800 cGy), and two prepubertal boys who received testicular irradiation. The incidence of clinically important growth and endocrine disorder in group II is $68 \%$.

TABLE V-Analysis of neuropsychological sequelae in 96 schoolchildren from group I (median in parentheses)

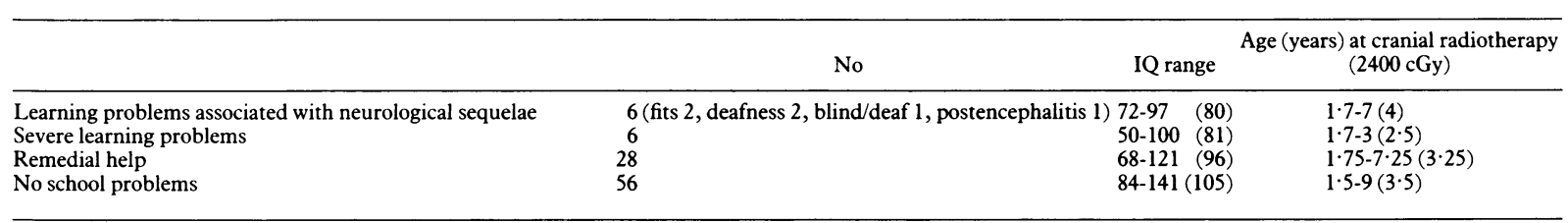

\section{GROWTH AND ENDOCRINE DEFICIENCY}

\section{Group I}

Of the 17 patients who had craniospinal radiotherapy, nine have appreciably reduced sitting height measurements (sitting height SD—subischial leg length $S D>-2$ ) indicative of spinal growth impairment, seven of whom have a final height within the normal range. The two other girls have a final height at less than the third centile.

Menarche occurred at between 10 and 16 years of age (median 12 years) in 55 of the 70 girls in group I. The ages of those who have not yet menstruated range from 8.5 to 11.5 years. Nine girls menstruated before 11 years of age (mean 10.5 ; range 10.0 to 10.8 years), and five others have evidence of early breast development (mean 8.8 years, range 8.6 to 9.0 years) with an early pubertal growth spurt. Three of these five have not yet menstruated, and two others menstruated at 11 years of age. Two boys also showed evidence of premature pubertal maturation with a testicular volume of $4 \mathrm{ml}$ at the age of 9 and 10 years respectively. Although the onset of puberty was within the normal range ( +2 to $+2 \cdot 5 \mathrm{SD}$ from mean) there was a greater proportion of children with early puberty than would be expected. ${ }^{17}$ Out of these 16 patients, two have a final height at less than the third centile, and 11 are within the normal range for British children. The three girls who have not yet menstruated have not achieved their final height, although one is predicted to be less than the third centile. We suspect that these children will have a decreased final height owing to advanced epiphysial maturation, which may be further compromised by impaired growth hormone secretion, which was not assessed. Three boys had constitutional delayed puberty. Two girls and one boy have normal healthy children.

\section{NEUROPSYCHOLOGICAL}

At the time of this study 96 of the 137 disease free survivors in group I were attending school, and 41 had left school. Of the 44 patients in group II, 32 children were attending school and 12 had left school. To analyse the neuropsychological sequelae of treatment in relation to the quality of life of these patients we studied the schoolchildren separately from those who have left school and are in further education or employed. In general the disease free long term survivors of group I have been more fully reassessed than the survivors who were treated again, many of whom have been on recurrent intensive treatment and for some of whom the long term outlook remains very poor.

\section{Group I}

Forty of the 96 schoolchildren (42\%) had an appreciable learning problem; of these, six had problems associated with neurological sequelae of treatment, six had very severe learning problems, and 28 , although attending "normal" schools, had required remedial help such as extra or individual tuition or had repeated a year at school or changed to a smaller, less academic school. Fifty three of the $\mathbf{9 6}$ schoolchildren had had crania radiotherapy ( $2400 \mathrm{cGy}$ ) before the age of 3 (seven before the age of 2). Twenty seven $(51 \%)$ of these had school difficulties. Forty three children had had cranial radiotherapy after 3 years of age, and of these, $13(30 \%)$ had difficulties at school. Table $\mathrm{V}$ gives an analysis of the neuropsychological sequelae in the 96 schoolchildren in group I. Almost all IQ assessments were 
made at least two years after treatment was stopped, and if several assessments were made the most recent was taken. The IQ values in the disease free survivors with learning difficulties were compared with those in the disease free survivors who had no learning problems. The values are significantly lower $(p=0.0001)$. There was no correlation between social class of parents, family instability, and the presence of learning problems.

Forty one of the group I patients have left school, their ages being 17-25 years. Thirty are employed: two in professional jobs, 18 in semiskilled posts, and nine in unskilled jobs. The types of employment are appropriate to the family's social class. Eight are attending further education courses, two are mothers, and only one is unemployed. None of these 41 older survivors have appreciable residual problems related to their leukaemia treatment.

\section{Group II}

Twelve of the 32 schoolchildren who were treated again (38\%) have problems associated with learning, two severe enough to require special schooling, while 10 have remedial help at school. Problems were least often found in children who received only one course of cranial irradiation, whereas half of those who had two courses of cranial irradiation and $80 \%$ who had cranial radiotherapy and subsequent total body irradiation have required special educational help (table VI). Five of the nine (55\%) patients who had their initial cranial radiotherapy at age 3 years or under have learning problems compared with seven of the $23(30 \%)$ who had it after their third birthday.

Of the 12 patients from group II who have left school, four are in employment, one in a skilled post, one in a semiskilled job, and two in unskilled jobs. Six are attending further education centres, one is unemployed, and one suffers from epilepsy and has a mental age of 2 after having had encephalitis (see next section). One girl who attends a rehabilitation centre has memory problems, a low IQ, a stiff gait, and computed tomographic changes secondary to methotrexate toxicity.

\section{POSTINFECTIVE RESULTS}

A small proportion of patients have severe residual problems from infective episodes during chemotherapy.

\section{Group I}

Eight of $137(6 \%)$ children in group I have postinfective problems. One has an extensive abdominal wall scar secondary to a pseudomonas cellulitis that occurred during treatment, and two have facial scars from varicella. Two children are deaf, require audiological supervision, and are using hearing aids. Both developed recurrent infective middle ear disease during treatment. A child who had a severe cytomegalovirus infection while having chemotherapy is blind and deaf, and two children now aged 11.5 and 14 years have major learning problems after unexplained episodes of encephalitis during treatment at ages 3 and $4 \cdot 5$ years.

\section{Group II}

Of the three children in group II with postinfective problems, one is deaf from recurrent infective middle ear disease and has received tympanoplasties, and two others are severely handicapped after encephalitis that occurred during treatment. One of these, now aged 22, suffers from epilepsy and has a mental age of 2 while the other, aged 13, has fits, facial weakness, and major learning problems.

\section{OTHER LONG TERM SEQUELAE OF TREATMENT}

\section{Group I}

An 11 year old has severe portal hypertension secondary to methotrexate induced hepatic fibrosis.

\section{Group II}

A 16 year old has portal hypertension secondary to methotrexate induced hepatic fibrosis. A further two patients who have had intermittent episodes
TABLE VI-Neuropsychological sequelae in 32 schoolchildren from group II (percentages in parentheses)

\begin{tabular}{|c|c|c|c|}
\hline Total radiotherapy & No & $\begin{array}{l}\text { Learning } \\
\text { problems }\end{array}$ & Comment \\
\hline Cranial once ${ }^{\star}$ & 17 & $3(18)$ & $\begin{array}{l}\text { One has severe problems, } \\
\text { postencephalitis +fits; } \\
\text { attends special school; } \\
\text { cranial radiotherapy age } 2\end{array}$ \\
\hline Cranial twice & 10 & $5(50)$ & $\begin{array}{l}\text { One has fits secondary to } \\
\text { methotrexate toxicity; } \\
\text { cranial radiotherapy age } 2\end{array}$ \\
\hline Total body irradiation $\neq+$ cranial once & 5 & $4(80)$ & $\begin{array}{l}\text { One has severe problems, } \\
\text { attends special school }\end{array}$ \\
\hline
\end{tabular}

*Cranial or craniospinal

tCranial and craniospinal: cranial twice, craniospinal twice.

(Cranial: $2400 \mathrm{cGy}$, craniospinal: cranial $2400 \mathrm{cGy}$, spinal $1000 \mathrm{cGy}$.) $\$ 1000$ cGy.

of haematuria have lower bladder telangiectasia presumed to be due to a combination of cyclophosphamide and radiation scatter from their testicular radiotherapy field. Five of the six patients who had bone marrow transplantation have cataracts, and one has severe pulmonary fibrosis after a pneumocystis pneumonia infection that occurred shortly after total body irradiation.

\section{Discussion}

The outcome for 181 survivors of a 10 year cohort of 378 children with acute lymphoblastic leukaemia shows that there is a price to pay for cure and a higher price for retrieval therapy. Forty two per cent (57) of the survivors in first remission and $82 \%$ (36) of those who relapsed were left with residual problems. In the patients who survived without relapse (group I) the major cause for concern is the high incidence of neuropsychological sequelae which present as a wide range of problems from specific severe neurological disorders to less severe learning, concentration, and educational difficulties and which must be attributed largely to the methods used to prevent overt leukaemic infiltration of the central nervous system. The association between cranial radiotherapy at a young age and subsequent learning difficulties is well known and our results have reconfirmed this. ${ }^{1-4}$ It must not be forgotten, however, that the high incidence of psychological and social problems in the families of children with leukaemia, together with poor school attendance, may exacerbate these learning difficulties. ${ }^{18}$ Over $40 \%$ of the survivors who are at school have learning difficulties compared with an estimated incidence of $20 \%$ in the school population as a whole. ${ }^{19}$

Assessments of IQ alone cannot identify the children with memory and learning problems, although the collective IQ values of the two groups of schoolchildren in long term first remission with and without learning difficulties are significantly different. It is essential to identify early the difficulties that some of these children may have at school as appropriate management of learning problems may greatly improve their progress at school. The results of recent work suggest that many of these children are better able to store visual material than auditory material,${ }^{20}$ which is relevant in their education.

In an attempt to reduce the incidence of neuropsychological sequelae the Medical Research Council working party and other collaborative groups have reduced the dose of cranial irradiation from $2400 \mathrm{cGy}$ to $1800 \mathrm{cGy}$. This lower dose has been shown to be as effective in the prevention of central nervous system relapse ${ }^{21}$ except perhaps in high risk patients, but there is no evidence yet that it reduces the incidence of subsequent learning difficulties. Other forms of central nervous system prophylaxis being studied include intrathecal methotrexate alone, ${ }^{22}$ moderate dose systemic methotrexate, ${ }^{23}$ and regular triple intrathecal chemotherapy (methotrexate, cytosine arabinoside, hydrocortisone) ${ }^{24}$ It remains to be determined whether these other methods which avoid cranial irradiation are less harmful, though the findings in a recent retrospective study seem to suggest this. ${ }^{25}$ The best method of preventing overt central nervous system leukaemia has yet to be 
determined and may vary with the age at diagnosis and the risk group.

The school leavers from group I are doing well: only one out of the 41 is unemployed. None of this group has problems related to the leukaemia treatment, perhaps because none had cranial irradiation at under 3 years of age compared with 43 of the 96 children who are still at school.

The endocrine morbidity in patients in both group I and group II is appreciable, but the incidence of serious endocrine deficiency is much higher in the patients in group II $(68 \%)$, who have often received high cumulative doses of cranial or craniospinal irradiation and testicular irradiation or total body irradiation. This has led to an appreciable incidence of growth hormone deficiency, ${ }^{7}$ gonadal failure ${ }^{26}$ and spinal shortening, ${ }^{27}$ which combined with prolonged ill health, steroid treatment, and chemotherapy gives rise to potentially severe growth failure. Fortunately, hormonal replacement alleviates much of this problem, but the effect of radiation on bone growth remains. The growth and endocrine morbidity associated with total body irradiation and bone marrow transplantation is very high, ${ }^{28} 29$ and multiple deficiencies have developed in five of the six patients who received bone marrow transplantation. Patients who receive total body irradiation as part of the preparative regimen for bone marrow transplantation are at great risk of gonadal and thyroid failure and growth hormone deficiency, ${ }^{28}{ }^{29}$ although the incidence of growth hormone deficiency may be reduced in patients without previous cranial radiotherapy. ${ }^{28} 29$ The main contribution to the incidence of endocrine morbidity $(20 \%)$ in group I was premature pubertal maturation, although most of the long term survivors first menstruated within the normal age range. Early puberty, which was commoner among the girls, may be associated with the effect of radiation on the hypothalamic-pituitary axis ${ }^{30}$ and may contribute to growth impairment. This is being further investigated. ${ }^{17}$ When combined with growth hormone deficiency the effect on growth may be disastrous, but treatment with a growth hormone releasing hormone analogue and growth hormone may improve prognosis in cases of radiation induced precocious puberty..$^{30}$ Although we did not detect growth hormone deficiency in patients in group I, we may have underestimated this problem. In the light of recent evidence it seems that growth hormone deficiency may be much more common than hitherto suspected in patients who receive $2400 \mathrm{cGy}$ or less. ${ }^{67}$ Minor degrees of growth impairment are reported to be widespread, ${ }^{68}$ but because our data are incomplete no conclusion can be drawn and further prospective longitudinal studies are required. Whereas endocrine dysfunction was found in many patients in group II, clinically important growth disorder requiring treatment was uncommon in patients in group $\mathrm{I}$.

Children with acute lymphoblastic leukaemia are at risk of certain infections throughout treatment, and it is not surprising that some patients show residual sequelae. Varicella should cause less morbidity now that the antiviral drug acyclovir is available. Encephalitis during treatment remains a poorly defined entity, whether it is due to infection or treatment, and the outcome is often very poor. Other organs that were susceptible to toxicity were the liver: two cases of methotrexate hepatic fibrosis ${ }^{31}$; and the eyes: five out of six bone marrow transplant recipients developing cataracts due to total body irradiation and possibly also to steroid treatment and one child blind after an infection with cytomegalovirus.

Our results show that over half of a cohort of 378 children with acute lymphoblastic leukaemia are alive six years or more after diagnosis - most in first remission and probably cured. Fifty eight per cent of these cured children, some now adolescents and adults, are entirely well and leading normal lives. Some, however, have paid a price for their cure, particularly in long term neuropsychological sequelae of treatment. Patients who have survived over five years after an isolated extramedullary relapse probably have a good chance of being "cured," but the morbidity associated with retreatment is very high, only $18 \%$ of them being "problem free." Our findings emphasise the importance of adequate first line treatment for acute lymphoblastic leukaemia rather than retrieval therapy: not only is the likelihood of survival much reduced once a relapse has occurred but so is the quality of life in most of those who are rescued.

Kate Wheeler was supported by the Leukaemia Research Fund and Alison Leiper is supported by the Medical Research Council. We thank Jeanette Stevens for typing the manuscript.

\section{References}

1 Soni SS, Marten GW, Pitner SE, Duenas DA, Powazek M. Effects of central nervous system irradiation on neuropsychologic functioning of children with acute lymphoblastic leukemia. N Engl F Med 1975;293:113-8.

2 Eiser C, Lansdown R. Retrospective study of intellectual development in children treated for acute lymphoblastic leukaemia. Arch Dis Child 1977;52:525-9.

3 Meadows A, Mowsari D, Fergusson J, Gordon J, Littman P. Decline in IQ scores and cognitive dysfunctions in children with acute lymphocytic leukaemia treated with cranial irradiation. Lancet 1981;ii: 1015-8.

4 Jannoun L. Are cognitive and educational development affected by an age at which prophylactic therapy is given in acute lymphoblastic leukaemia. Arch Dis Child 1983;58:953-8.

5 Shalet SM, Beardwell CG, Twomey JA, Morris-Jones PM, Pearson D. Endocrine function following the treatment of acute leukemia in childhood. F Pediatr 1977;90:920-3.

6 Kirk JA, Stevens MM, Menser MA, et al. Growth failure and growth hormone deficiency after treatment for acute lymphoblastic leukaemia. Lancet 1987;i:190-3.

7 Shalet SM. Irradiation-induced growth failure. Clin Endocrinol Metab 1986;15:591-666.

8 Robison LL, Nesbit ME, Sather HN, Meadows AT, Ortega JA, Hammond GD. Height of children successfully treated for acute lymphoblastic leukaemia: a report from the Late Effects Study Committee of the Children's Cancer Study Group. Med Pediatr Oncol 1985;13:14-21.

9 Chessells JM, Ninane J, Tiedemann K. Present problems in management of childhood lymphoblastic leukaemia: experience from the Hospital for Sick Children, London. Modern trends in human leukaemia IV. Heidelberg: Springer, 1981:108-14.

10 Tanner JM, Whitehouse RH, Takaishi M. Standards from birth to maturity for height, weight, height velocity and weight velocity: British children, 1965. Arch Dis Child 1966;41:613-35.

11 Stanhope R, Brook CGD. The clinical diagnosis of disorders of puberty: the loss of consonance. Brf Hosp Med 1986;35:57-8.

12 Tanner JM, Whitehouse RH, Cameron N, Marshall WA, Healy MJR, Goldstein H. Assessment of skeletal maturity and prediction of adult height (TW2 method). London: Academic Press, 1983.

13 Hughes IA. Handbook of endocrine tests in children. Bristol: Wright, 1980.

14 Hirot C, Murray D, Pearson L. Bristol ability scales. Windsor: National Foundation for Educational Research, 1978.

15 Wechsler D. Wechsler intelligence scale for children: revised. New York: Psychological Corporation, 1974.

16 Chessells JM, Hardisty RM, Richards S. Long survival in childhood lymphoblastic leukaemia. Brf Cancer 1987;55:315-9.

17 Leiper AD, Stanhope R, Kitchings P, Chessells JM. Precocious and premature puberty associated with the treatment of acute lymphoblastic leukaemia. Arch Dis Child (in press).

18 Maguire P, Comaroff J, Ramsell PJ, Jones PHM. Psychological and social problems in families of children with leukaemia. In: Morris Jones PH, ed. Topics in paediatrics I. Haematology and oncology. Tunbridge Wells: Pitman Medical, 1979:141-9.

19 Committee of Enquiry into the Education of Handicapped Children and Young People. Special educational needs. London: HMSO, 1978.

20 Jannoun L, Chessells JM. Long-term psychological effects of childhood leukaemia and its treatment. Paediatric Haematology and Oncology (in press).

21 Nesbit ME, Sather HN, Robison LL, et al. Presymptomatic central nervous system therapy in previously untreated childhood acute lymphoblastic leukaemia. Comparison of $1800 \mathrm{rad}$ and 2400 rad. Lancet $1981 ; \mathrm{i}: 461-5$.

22 Bleyer WA, Nickerson J, Coccia P, et al. Monthly pulses of vincristine and prednisolone (VIP) prevent marrow and testicular relapse in childhood acute lymphoblastic leukemia (ALL): one conclusion of the CCG161 study of good prognosis ALL. Proceedings of the American Society of Clinical Oncology 1985;4:160.

23 Moe PH, Seip M, Finne PH. Intermediate dose methotrexate (IDM) in childhood acute lymphocytic leukaemia in Norway. Acta Paediatr Scand 1981;70:73-9.

24 Sullivan MP, Chan T, Dymont PG, Hvizdala E, Steuber CP. Equivalence of intrathecal chemotherapy and radiotherapy as central nervous system prophylaxis in children with acute lymphoblastic leukemia: a Pediatric Oncology Group Study. Blood 1982;60:948-58.

25 Rowland JH, Glidewell OJ, Sibley RF, et al. Effects of different forms of central nervous system prophylaxis on neuropsychological function in childhood leukaemia. $\mathcal{J}$ Clin Oncol 1984;2: prophylaxis.

26 Leiper AD, Grant DB, Chessells JM. Gonadal function after testicular radiation for acute lymphoblastic leukaemia. Arch Dis Child 1986;61:53-6.

27 Plowman PN. Endocrine effects of therapy. In: Jung R, Sikora K, eds. Endocrine problems in cancer. London: Heinemann, 1984:255-73.

28 Sanders JE, Pritchard S, Mahoney P, et al. Growth and development following marrow transplantation for leukemia. Blood 1986;68:1129-35.

29 Leiper AD, Stanhope R, Lau T, et al. The effect of total body irradiation and bone marrow transplantation during childhood and adolescence on growth and endocrine function. $\mathrm{Br} F$ Haematol (in press)

30 Brauner R, Rappapart R. Precocious puberty secondary to cranial irradiation for tumours distant from the hypothalamopituitary area. Hormone Res 1985;22:78-82.

31 Nesbit M, Krivit W, Heyn R, Sharp H. Acute and chronic effects of methotrexate on hepatic, pulmonary and skeletal systems. Cancer 1976;37:1048-54.

(Accepted 2 October 1987) 